\title{
Probability learning and attitude toward women as a function of monetary risk, gain, and sex
}

\author{
GLORIA J. FISCHER \\ Washington State University, Pullman, Washington 99163
}

\begin{abstract}
When prediction involved the risk of losing a small amount of money, college students achieved statistical maximizing on a probability learning task. The possibility of winning the same small amount of money was less effective. Males outperformed females on the probability learning task. This was unrelated to the literalness of subjects' scores on the attitudes toward women scale, but the latter scores were affected by the sex of the subject and experimenter. Specifically, women seemed to score according to "demand characteristics," that is, according to what a male or female experimenter might expect of them; whereas men tested by women seemed to show the "screw you" effect, that is, they scored more conservatively than when tested by a male.
\end{abstract}

In two-choice probability learning humans are asked to predict which one of two events will occur on successive trials, where the events occur with probabilities $\pi$ and $(1-\pi)$. In contrast to infrahuman species, only rarely do human subjects predict the most frequently occurring event (an $\mathbf{A}_{1}$ prediction) in greater proportion (p) than $\pi$. One of the few times they do tend to overshoot $\pi$ [i.e., show $\mathrm{p}\left(\mathrm{A}_{1}\right)>\pi$ ] is if they win and lose money as a consequence of making correct and incorrect predictions, respectively (e.g., Siegel \& Goldstein, 1959). Since winning and losing money have not been varied independently, their relative importance in producing overshooting is not known.

Evidence suggests that humans tend to predict the event that will minimize loss rather than maximize gain (Myers, Reilly, \& Taub, 1961). They also prefer a low probability of losing large amounts of money to a high probability of losing small amounts, that is, people do not like to lose (Edwards, 1954). Thus, winning may affect $\mathrm{p}\left(\mathrm{A}_{1}\right)$ independently of, and perhaps less than, the possibility of losing (Katz, 1964). This latter possibility was assessed in Experiment 1 of the present study by varying gain and loss factorially in a probability learning study. Specifically, college students (1) could lose money when wrong, but not win when right, (2) could win but not lose, (3) could win and lose, or (4) could neither win nor lose. Results showed that the possibility of losing (risk) was indeed more important than the possibility of winning (gain). For example, only risk significantly enhanced $\mathrm{p}\left(\mathrm{A}_{1}\right)$ under all conditions for both male and female students.

\section{EXPERIMENT 1: RISK, GAIN, AND SEX-OF-SUBJECT EFFECTS ON PROBABILITY LEARNING}

\section{Method}

Subjects. The subjects were 32 male and 32 female fresh-

Findings were presented at meetings of the Midwestern Psychological Association, May 1975, in Chicago. man students from introductory psychology. Their participation fulfilled a course requirement.

Procedure. Each subject was asked to predict the color of every playing card in three 100 -card decks, each of which contained either 70 red cards and 30 black cards (35 diamonds, 35 hearts, 15 clubs, and 15 spades) or 70 black and 30 red cards. The order of card colors was randomized by use of an automatic card shuffler. Students predicted each card's color successively through the three decks, turning each card over to see if he or she was correct.

An equal number of male and female students were assigned randomly to four groups ( $=16$ per group). A control group (no risk, no gain) was told to try to make as many correct predictions as possible over the entire 300 cards (trials). A second group (gain), was told they would win 2 cents for every correct prediction and could keep all they won in excess of $\$ 3.50$. A third group (risk) was advanced $\$ 3.50$ and told they would lose 2 cents for every incorrect prediction, but could keep whatever amount they had left at the end of the experiment. Students in a fourth group (gain and risk) were given $\$ 1.00$ and told they would win or lose 2 cents for correct or incorrect predictions, respectively, and could keep any money they made in excess of $\$ 2.30$. (The amounts of money advanced and the amounts students had to exceed to win were derived from, and equated for, estimated zero gain, assuming matching of $\pi$.)

\section{Results}

The proportions of most frequent event predictions, per subject, per block of 100 trials, were analyzed using a $2^{3}$ by 3 (risk by gain by sex-of-subject by blocks) factorial design analysis of variance with repeated measures over blocks. As expected, results showed that risk enhanced $\mathrm{p}\left(\mathrm{A}_{1}\right)$ [for the Risk by Block interaction, $\mathrm{F}(2,122)=6.55, \mathrm{p}<.01]$. As can be seen in Figure 1, $\mathrm{p}\left(\mathrm{A}_{1}\right)$ under risk conditions increased over 100-trial blocks to a statistical criterion of maximizing (see Bravemen \& Fischer, 1968) by the third block of 100 trials. In no-risk conditions, on the other hand, $\mathrm{p}\left(\mathrm{A}_{1}\right)$ increased only to matching of $\pi$. Like risk, gain also tended to produce maximizing in males [i.e., male $\mathrm{p}\left(\mathrm{A}_{1}\right)=.80$ by Block 3], but not in females [Gain by Sex effect, $F(1,56)=11.1, p<.01]$. As can be seen in Table 1, males, but not females, performed better with gain than without it $[F(1,56)=9.15, p<.01]$.

Findings from Experiment 1 support the conclusion 


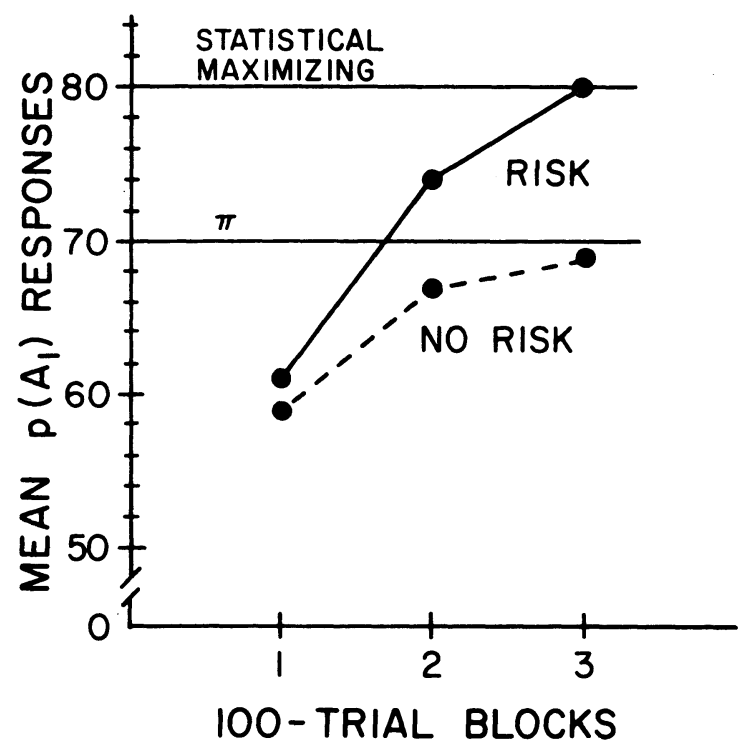

Figure 1. Mean proportion of most frequent event predictions under risk and no-risk conditions, over trial blocks.

Table 1

Mean Proportion of Most Frequent Event Predictions, p $\left(A_{1}\right)$, as a Function of Gain and Sex of Subject

\begin{tabular}{cccc}
\hline & & \multicolumn{2}{c}{ Sex of Subject } \\
\cline { 3 - 4 } & & Male & Female \\
\hline \multirow{4}{*}{ Gain } & Yes & .73 & .63 \\
& No & .67 & .72 \\
\hline
\end{tabular}

that risk generally is more effective than gain in producing more rational prediction behavior in humans. Risk even produced statistical maximizing, that is, an asymptotic $\mathrm{p}\left(\mathrm{A}_{1}\right)$ significantly greater than $\pi$, in support of Siegel's utility theory. Infrahuman species, including nonhuman primate, carnivore, rodent, and avian forms, do even better on probability learning. However, it is common for infrahuman animals to be tested under high deprivation, and thus, food reward has great utility. If humans were tested with comparably great utility of reward, that is, with substantially greater payoff, or, especially, a much greater risk than merely losing two or three of someone else's dollars, as in the present study, humans probably would predict optimally, too.

As noted previously, findings from Experiment 1 suggested a possible sex difference in probability learning. Both men and women students performed better with risk than without it. Men also tended to perform better with gain than without it, while women tended to perform worse. This difference might arise from differences in cultural sex roles. For example, men are encouraged to compete, to win, whereas women are discouraged from competing to win, especially against males. In this regard, it may have been significant that the experimenter was male and/or that he was a handsome, jock-type male.
Some sex differences found in the "prisoner's dilemma," a game that requires cooperative play for optimal gain (see Vinacke, 1969), seem inconsistent with the suggested cultural sex role interpretation. For example, women make fewer competitive responses when playing against a male, as opposed to a female opponent, but they also make absolutely more competitive responses than males do (Rapoport \& Chammah, 1965). If differing cultural sex roles did underlie the sex effect found in Experiment 1, performance of women under gain conditions might be expected to relate to the sex of the experimenter and/or their own attitudes toward women. Experiment 2 was designed to assess these possibilities.

\section{EXPERIMENT 2: EFFECT OF MONETARY RISK, GAIN, SEX OF SUBJECT AND EXPERIMENTER, AND ATTITUDES TOWARD WOMEN ON PROBABILITY LEARNING}

\section{Method}

Subjects $(\mathrm{N}=192)$ and procedure replicated Experiment 1 , with two exceptions. First, 24 male and 24 female subjects were assigned randomly to each of two male and two female experimenters. Second, after completing the probability learning task, each subject was individually administered the Spence and Helmreich (1972) attitudes toward women (AWS) scale.

\section{Results and Discussion}

As in Experiment 1, variation in $\mathrm{p}\left(\mathrm{A}_{1}\right)$, per subject, per 100 -trial block, was analyzed using a $2^{5}$ by 3 (risk by gain by sex of subject by sex of experimenter pair by blocks of 100 trials) repeated measures design analysis of variance. (The experimenter-pair factor was an optional inclusion, based on the fact that one malefemale experimenter pair tested subjects in one room, whereas the other pair tested subjects in a different room.) Correlational analysis assessed the relation between AWS scores and $\mathrm{p}\left(\mathrm{A}_{1}\right)$, and an analysis of covariance in $\mathrm{p}\left(\mathrm{A}_{1}\right)$ was performed using AWS score as a covariate. The correlational analyses and analyses of covariance were performed twice, once using all subjects and once using only females in no-risk groups.

The analysis of variance in $p\left(A_{1}\right)$ responding revealed statistically reliable risk and sex-of-subject effects. As in Experiment 1, risk produced a higher $\mathrm{p}\left(\mathrm{A}_{1}\right)$ than no risk $[F(1,160)=16.6, p<.01]$. The asymptotic level of $p\left(\mathrm{~A}_{1}\right)$ (Trials 201-300) was .79 under risk, .72 under no risk. The sex-of-subject $F(1,160)=3.94, p<.05$ showed that males performed better than females. Asymptotic $\mathrm{p}\left(\mathbf{A}_{1}\right)$ was .77 for males and .73 for females. Thus, both Experiments 1 and 2 showed that risk enhanced $\mathrm{p}\left(\mathbf{A}_{1}\right)$. Experiment 2 also showed males superior to females, but failed to replicate the sex-of-subject by gain effect found in Experiment 1.

Why the failure in Experiment 2 to replicate the sexof-subject by gain effect found in Experiment 1? Experiment 2 followed by Experiment 1 by 3 years, during which time a change in attitudes toward women 
could have taken place. For example, AWS scores in Experiment 2 were slightly higher (more liberal) than those in the Spence and Helmreich (1972) sample [Experiment 2 mean AWS scores for males $=94.8$, females $=103.6$. In the Spence and Helmreich (1972) study mean AWS scores for males $=92.9$, females = 101.0]. However, AWS scores did not relate to $p\left(A_{1}\right)$ responding in probability learning. With a wide range of scores, the correlation was -.10 for all subjects and for women subjects in no-risk conditions, $\mathrm{r}=-.13$. Similarly, when a subject's score was used as a covariate, it failed to account for a significant amount of $p\left(A_{1}\right)$ variance. Thus, AWS scores did not predict $\mathrm{p}\left(\mathrm{A}_{1}\right)$ responding. Another possibility is that the sex of subject by gain effect found in Experiment 1 was due to the attractive, jock-type male experimenter. Such a male may intimidate some women, regardless of their attitudes toward women. That is, they may feel more pressure from such males to conform to a conservative (submissive) role, and they do so, as a result of earlier, long-term conditioning.

Since the probability learning task was given to all subjects first, and the AWS scale second, the factors varied experimentally in Experiment 2 could have influenced AWS scores, as well as $\mathrm{p}\left(\mathrm{A}_{1}\right)$ responding. Consequently, the analysis of variance performed on $p\left(A_{1}\right)$ also was performed on AWS scores, with elimination of one factor, blocks of 100 trials. Results of that analysis revealed a Sex of Subject by Sex of Experimenter interaction $[F(1,160)=6.50, p<.01]$.

The nature of that effect (see Table 2) was quite unexpected. As can be seen in Table 2, females scored higher (more liberally) than males, but when females were administered the AWS scale by females, they

Table 2

Mean Attitudes Toward Women (AWS) Scale Scores as a Function of Sex of Subject and Sex of Experimenter

\begin{tabular}{lllc}
\hline & & \multicolumn{2}{c}{ Sex of Experimenter } \\
\cline { 3 - 4 } & & Male & Female \\
\hline \multirow{2}{*}{ Sex of Subject } & Male & 97.3 & 92.2 \\
& Female & 98.7 & 108.5 \\
\hline
\end{tabular}

scored higher than when they were administered the scale by males. In contrast, male subjects did just the opposite. Stated differently, how liberally men and women score on attitudes toward women depends very much on the sex of the person administering the scale. In the case of women, the difference seems to fit the "demand characteristics" of the situation (Orne, 1962, as cited in Masling, 1966). That is, women score lower on AWS when tested by men, whom they might think expect or prefer conservative opinions. Men, on the other hand, do not score according to demand characteristics and, instead, seem to show the "screw you" effect (Masling, 1966). That is, they actually score more conservatively on attitudes toward women when tested by female experimenters than when tested by male experimenters.

\section{REFERENCES}

Braveman, N. S., \& Fischer, G. J. Instructionally induced strategy and sequential information in probability learning. Journal of Experimental Psychology, 1968, 76, 674-676.

Edwards, W. The theory of decision making. Psychological Bulletin, 1954, 51, 380-417.

KATZ, L. Effects of differential monetary gain and loss on sequential two-choice behavior. Journal of Experimental Psychology, 1964, 60, 245-249.

MaSLING, J. Role-related behavior of the subject and psychologists and its effects upon psychological data. In D. Levine (Ed.), Nebraska symposium on motivation. Lincoln: University of Nebraska Press, 1966

Myers, J. L., Reilly, R. E., \& TAUB, H. A. Differential cost, gain and relative frequency of reward in a sequential choice situation. Journal of Experimental Psychology, 1961, 62, 357-360.

Siegel, S., \& Goldstein, D. Decision-making behavior in a twochoice uncertain outcome situation. Journal of Experimental Psychology, 1959, 57, 37-42.

Spence, J. T., \& Helmreich, R. The attitudes toward women scale: An objective instrument to measure attitudes toward the rights and roles of women in contemporary society. Journal Supplement Abstract Service, 1972, 2, 66.

Rapoport, A., \& Chammah, A. M. Sex differences in factors contributing to the level of cooperation in the prisoner's dilemma game. Journal of Personality and Social Psychology, 1965, 2, 831-838.

VinACKE, W. E. Variables in experimental gains: Toward a field theory. Psychological Bulletin, 1969, 71, 293-318.

(Received for publication October 18, 1976.) 